\title{
O RETORNO DO EXILADO EM \\ O ANO DA MORTE DE RICARDO REIS, DE JOSÉ SARAMAGO
}

Tiago Ribeiro dos Santos*

\begin{abstract}
RESUMO: Este artigo contempla um estudo da obra de Saramago em consonância com o conceito de flaneur cunhado por Walter Benjamim. Procuramos esboçar como o personagem diaspórico pode ser encarado como um andarilho que perambula pelas ruas de Lisboa em meio ao conturbado ano de "mau tempo".
\end{abstract}

PALAVRAS-CHAVE: Ricardo Reis; flaneur; História; diáspora.

ABSTRACT: This article includes a study of Saramago's text in alignment with the concept of flaneur coined by Walter Benjamin. We intend to outline how the diasporic character can be seen as a drifter who wanders the streets of Lisbon in the midst of "the bad weather" of a troubled year.

KEYWORDS: Ricardo Reis; flaneur; History; diaspora.

O ano da morte de Ricardo Reis enseja, entre outras, discussões a respeito dos limites entre Literatura e História, tendo em vista que seu autor se apropria de eventos da História portuguesa e europeia, sobretudo do ano de 1936, para compor não somente o cenário do romance, mas para estruturá-lo a partir do questionamento feito pelo narrador e pelas personagens a respeito dos fatos históricos. Ricardo Reis, ao se contentar apenas com o espetáculo do mundo, toma conhecimento do panorama político-social de sua nação a partir das notícias dos jornais que lê. O discurso panfletário da imprensa, a vangloriar o sistema de governo vigente, passa, ironicamente, meio que despercebido pelos olhos de Ricardo Reis, o qual não tece nenhum tipo de reflexão crítica a respeito do posicionamento dos jornais sobre os fatos noticiados.

Mesmo sem tecer maiores reflexões a respeito das notícias veiculadas pelos jornais, o flaneur Ricardo Reis, que perambula pelas ruas de Lisboa, escuta a voz dissonante de Lídia, que por sua vez reproduz as ideias esquerdistas de seu irmão, o marinheiro Daniel. É essa voz dissonante, juntamente com as falas do narrador irônico de Saramago, que arquiteta o texto em diálogo com os fatos históricos. Longe simplesmente de reproduzi-los, o narrador altera o olhar sobre a História, veiculando um discurso outro, diferente daquele veiculado pela História Oficial. Se a Ditadura era

Mestrando em Teoria Literária pela Universidade Federal de Santa Catarina. 
vista com bons olhos pelos jornais, a ironia do narrador infunde outro sentido para as informações, apresentando justamente o ponto de vista contrário ao do sistema. É interessante notar, acima de tudo, que mesmo sendo um romance que apresenta uma enxurrada de fatos do ano de 1936, tem como personagem central um sujeito eminentemente ficcional. Por isso, não há um sujeito histórico que se ficcionaliza na obra, mas uma personagem da ficção que se torna sujeito na História criada por Saramago.

Uma outra consideração importante diz respeito à situação do tempo, ao clima chuvoso no evento da chegada e permanência de Ricardo Reis em Lisboa. O permanente mau tempo prefigura uma metáfora da ditadura, quando Lisboa é alagada pela água e sufocada pelo governo de Salazar. A água, aqui, deixa de apresentar o sentido de elemento purificador, para infundir ao texto o sentido de água que afoga, que suprime as palavras, que faz calar e dar vazão ao silêncio. Segundo Isabel Margato,

\begin{abstract}
Essa Lisboa é "sombria" e "recolhida" sob o peso de "águas turvas" que são o próprio reverso daquelas que espelhavam o céu azul metáfora de um passado de glórias. Mesmo que esse tempo não tenha existido exata e totalmente "em glórias", foi o que se pensou por muito tempo como verdadeiro, ou o que por muito tempo passou como verdadeiro. Mas as águas presentes agora são outras. São turvas. E a Lisboa que visitamos nesse romance é a Lisboa silenciada pelas sombras cinzentas de um ano de mau tempo. (MARGATO, p. 146)
\end{abstract}

O encontro de Ricardo Reis com essa Lisboa afogada em águas é o encontro do sujeito que (re)visita sua terra natal e o seu estado de "ser" no mundo, depois da morte de Fernando Pessoa, anunciada pelo bilhete de Álvaro de Campos e mais tarde confirmada pela notícia do jornal. Essa pretensão a uma identidade flui de maneira muito sutil ao longo do romance e define-se, principalmente, pela situação de errância do poeta a perambular pelas ruas de Lisboa. De início, há o quarto de hotel - que demarca o ambiente próprio do trânsito, de pessoas que vêm e vão, o entre-lugar de sujeitos que perambulam e vagueiam - a receber os cuidados de Lídia, não a mulher que costumava cantar em suas odes, mas a outra, da qual utiliza-se de favores sexuais. A igualdade daqueles que frequentam quartos de hotel pode ser associada àquela descrita por Walter Benjamim quando se refere aos personagens da multidão, em que "o inferior está disfarçado em superior", sem diferenças que os possam separar. 
A condição burguesa de Ricardo Reis, que lhe permite demorar a sair do Hotel Bragança e se instalar na casa no Alto de Santa Catarina, sem ao menos se preocupar em ter um trabalho fixo, faz desse sujeito-poeta um ser capaz de redescobrir Lisboa, uma Lisboa mudada, após dezesseis anos de autoexílio no Brasil. As suas andanças, além de lhe despertarem sensações a partir dos lugares que visita, despertam-lhe dados da memória, com relação às impressões experimentadas num outro tempo. A respeito disso, assinala Benjamin:

Aquela embriaguez anamnéstica em que vagueia o flaneur pela cidade não se nutre apenas daquilo que, sensorialmente, lhe atinge o olhar; com frequência também se apossa do simples saber, ou seja, de dados mortos, como de algo experimentado e vivido. (BENJAMIN, 1994, p. 187)

Benjamim afirma que a rua conduz o flanador a um tempo desaparecido e, a partir disto, estabelece uma relação com o poeta Baudelaire, que perambulava pelas ruas de Paris a encontrar-se com seu passado, com suas origens particulares e com o tempo perdido da sua infância. Da mesma forma que o vagar pela cidade, esta tida como o autêntico chão sagrado da flaneurie, possibilita o encontro do poeta consigo mesmo, essa atitude também permite o encontro do poeta com o passado histórico da cidade, que se espelha em suas calçadas, ruas e pontes.

Esse passado coletivo, resgatado por Baudelaire no seu ritual viageiro pelas ruas de Paris, relaciona-se em certa medida ao resgate de um tempo glorioso que se pode ler nas entrelinhas do romance de Saramago quando, a todo o tempo, Ricardo Reis norteiase em Lisboa a partir da estátua de Camões e, por vezes, a partir do monumento do Gigante Adamastor. Esse passado mítico é constantemente reatualizado por Ricardo Reis na sua atitude de flaneur que vagueia pelas ruas da capital portuguesa, já que se orienta no presente a partir de estruturas mítico-simbólicas do passado coletivo de Portugal.

Ao lado de seus outros heterônimos, Fernando Pessoa esbarra-se na criação de um poeta clássico, em pleno auge da modernidade. Justamente neste período, quando fervilham modelos de novidade instaurados pelas escolas de Vanguarda, como o Surrealismo, o poeta da geração de Orpheu aposta num heterônimo devoto da lei da ataraxia, cujo objetivo é evitar qualquer tipo de movimento. Ricardo Reis, como um 
poeta detentor da sabedoria da contemplação, tem a pretensão de não se envolver profundamente com as dores do mundo, se é que isso é possível na condição de poeta. Mesmo assim, produz grande parte de sua obra dedicada a Lídia, a exemplo do famoso poema "Vem sentar-te comigo, Lídia, à beira do rio" (PESSOA, s/d, p. 126-127).

Dos textos da obra heteronímica de Fernando Pessoa atribuídos a Ricardo Reis para o romance de Saramago, temos um deslocamento da figura da mulher. A figura mitológica e divinizada da Lídia cantada nas odes é substituída pela condição de mulher trabalhadora da Lídia da obra de Saramago. Por meio das palavras de Fernando Pessoa, num de seus encontros com Reis, fica explícito esse deslocamento:

É mulher, Bravo, vejo que você se cansou de idealidades femininas incorpóreas, trocou a Lídia etérea por uma Lídia de encher as mãos, que eu bem a vi lá no hotel, e agora está aqui à espera doutra dama... (SARAMAGO, 1989, p. 182)

Em O Ano da Morte de Ricardo Reis há uma dessacralização da figura feminina, enquanto fruto de um deslocamento que modifica a posição de um sujeito no contexto da obra literária. O tom célebre e ilustre das odes de Ricardo Reis atesta a forma grandiosa e solene do eu-lírico ao se reportar à figura de Lídia, a musa inspiradora. Esse tom celebratório é, de certa forma, modificado, para dar lugar a um outro tipo de discurso na narrativa de Saramago. A Lídia, criada do hotel em que Ricardo Reis se hospeda em Lisboa, é construída com uma identidade tão peculiar que a torna diferente (e não menor) em relação à Lídia das odes. A relação que Ricardo Reis mantém com a criada do hotel é destituída de formalidades e presta-se, na maioria das vezes, a objetivos puramente sexuais. Ricardo Reis, assim como nega qualquer tipo de movimento, para evitar que venha a se perder, nega também as paixões e o amor, já que, para ele, todo homem está fadado ao prodígio dos deuses. Não podemos deixar de notar, é claro, que, apesar de a Lídia do romance ser uma personagem da classe social menos favorecida, ela funciona como o arauto do discurso político esquerdista presente ao longo da obra. É por meio do discurso denunciador da voz de Lídia que Saramago produz o ponto de vista contrário ao da História Oficial. A voz dissonante que ecoa dos lábios desta personagem denuncia o esquema político marcado pelas incertezas do ano de 1936, como pode ser observado na seguinte passagem: 
O senhor doutor é uma pessoa instruída, eu sou quase uma analfabeta, mas uma coisa eu aprendi, é que as verdades são muitas e estão umas contra as outras, enquanto não lutarem nunca se saberá onde está a mentira, E se é verdade terem arrancado os olhos ao padre, se o regaram com gasolina e queimaram, Será uma verdade horrível, mas o meu irmão diz que se a igreja estivesse do lado dos pobres, para os ajudar na terra, os mesmos pobres seriam capazes de dar a vida por ela, para que ela não caísse no inferno, onde está, E se cortaram as orelhas aos proprietários, se violaram as mulheres deles, Será outra horrível verdade, mas o meu irmão diz que enquanto os pobres estão na terra e padecem nela, os ricos já vivem no céu vivendo na terra, Sempre me respondes com as palavras do teu irmão, E o senhor doutor fala-me sempre com as palavras dos jornais. Assim é. (SARAMAGO, 1989, p. 387-388)

Assim como a voz "subversiva" de Lídia, que contraria a visão da História de Portugal no ano de 1936 noticiada pelos grupos de direita da época, há também a voz marcante do narrador, postulada de intromissões e sussurros, o que nos lembra o narrador de muitas narrativas de Machado de Assis, que, mesmo sem se constituir como personagem ativo da história, deixa suas marcas a todo o tempo no relato.

O Ano da Morte de Ricardo Reis é uma obra que suscita, entre outras leituras, uma reflexão a respeito da identidade do sujeito. É a partir da morte de Fernando Pessoa, anunciada pelo bilhete de Álvaro de Campos, que faz com que Reis parta para Lisboa após um período de dezesseis anos de autoexílio no Brasil. Se pensarmos na condição heteronímica de Ricardo Reis, como sujeito inscrito numa identidade produzida pelo poeta, podemos afirmar que é somente a partir da morte de Fernando Pessoa que o heterônimo pessoano pode, então, se autoafirmar como sujeito. No romance de Saramago, esta autoafirmação se dá na medida em que Ricardo Reis fala da morte de Fernando Pessoa. É o ato de se reportar à figura do demiurgo, utilizando como instrumento a linguagem, que Ricardo Reis se afirma como sujeito no mundo. Para isso, utiliza-se da liberdade que tem, enquanto poeta e enquanto médico, embora nenhuma dessas funções seja exercida com afinco por ele.

A discussão a respeito da identidade de Ricardo Reis flui ao longo de todo o romance. Ao chegar em Lisboa depois de desembarcar do navio Highland Brigade que o trouxera do Brasil, Reis revela ao motorista, no caminho até o hotel Bragança, que tem identidade portuguesa e que passara dezesseis anos fora do país. O hotel, como local próprio do trânsito e vida suspensa, para utilizar as palavras de Ricardo Reis, é o ambiente que acolhe o heterônimo pessoano em Lisboa. É neste local, marcado como 
um entre-lugar na vida de Reis - a situar-se no momento intervalar entre a saída do Brasil e a posterior instalação na casa do Alto de Santa Catarina - que o poeta assume inicialmente a condição de flaneur. Ricardo Reis tem sua estada em Portugal marcada por um perambular constante pelas ruas de Lisboa. E é justamente nessa deambulação que se inscreve um ciclo de formação da sua identidade, a qual não se define até a última página do romance. Ricardo Reis, em certa passagem, quando observa as ondas do rio a se desfazerem na muralha, alimenta uma dúvida de cunho existencial: "Lembrase de ali ter sentado em outros tempos, tão distantes que pode duvidar se os viveu ele mesmo. Ou alguém por mim, com igual rosto e nome.” (SARAMAGO, 1989, p. 33-34).

Acreditamos que, apesar de Ricardo Reis autoafirmar-se como sujeito após a morte de Fernando Pessoa, sua identidade ainda apresenta certas fissuras, dadas as constantes aparições de Pessoa ao longo da narrativa. Este sujeito post mortem que, assim como Reis, também perambula pelas ruas encharcadas de água no ano de mau tempo que a obra enseja, acaba por se tornar uma figura mítica tal como o Encoberto, de cuja crença se alimenta o imaginário português. A Lisboa inundada pelas águas e pelo clima de inconstância da nação subjugada pela ditadura de Salazar tem, agora, como sujeito que perambula pelas ruas da cidade a figura fantasmagórica de Fernando Pessoa.

Nesse ínterim, ao contrário de D. Sebastião, que permanece encoberto, Fernando Pessoa pode ser tido como o revelado, já que se apresenta a Ricardo Reis e o convida a partir para um local de que o leitor não toma conhecimento. Tal como anunciou Fernando Pessoa em Mensagem por meio da expressão É a hora!, o mito do Sebastianismo também pode ser desdobrado em O Ano da Morte de Ricardo Reis como a epifania do poeta e do heterônimo, que juntos partem, encerrando a narrativa de Saramago.

De origem grega, o termo epifania designa "manifestação" ou "aparição" e era utilizado no contexto anterior ao Cristianismo para se referir às aparições dos deuses. A partir da era cristã, este termo passou a designar a aparição de Cristo para os Reis Magos, celebrada no dia 06 de Janeiro pela Igreja. O escritor James Joyce apropriou-se do termo e deu a ele um significado na literatura, o qual se institucionalizou no vocabulário crítico de nossa tradição literária. $\mathrm{Na}$ economia ficcional do romance de 
Saramago, o conceito de epifania nos auxilia na leitura do desfecho da obra, quando, “naturalmente”, Fernando Pessoa convida Ricardo Reis a partir.

Enquanto supomos que Ricardo Reis está inscrito numa materialidade - que é a condição sine qua non para a existência humana -, Fernando Pessoa não passa de um fantasma a fazer algumas aparições para o heterônimo. E a última destas aparições é crucial para o desfecho do romance, pois é a grande revelação, o momento epifânico por excelência, uma vez que Reis - com sua suposta materialidade -, decide compartilhar da vida imaterial de seu criador. $\mathrm{O}$ ato de aceitar partir na companhia de Pessoa, com a tamanha naturalidade relatada pelo narrador, deflagra aquilo que o romance parece esconder do leitor: o suposto caráter de fantasmagoria de Ricardo Reis.

É em meio a um ano de mau tempo, onde tudo é incerto no cenário político, que Portugal faz-se nevoeiro. Nas célebres palavras de Fernando Pessoa em Mensagem, o tom de profecia da terceira parte (O Encoberto) pode ser lido nas entrelinhas do romance de Saramago com um tom de despedida, dada a partida do retornado e do poeta que o criou:

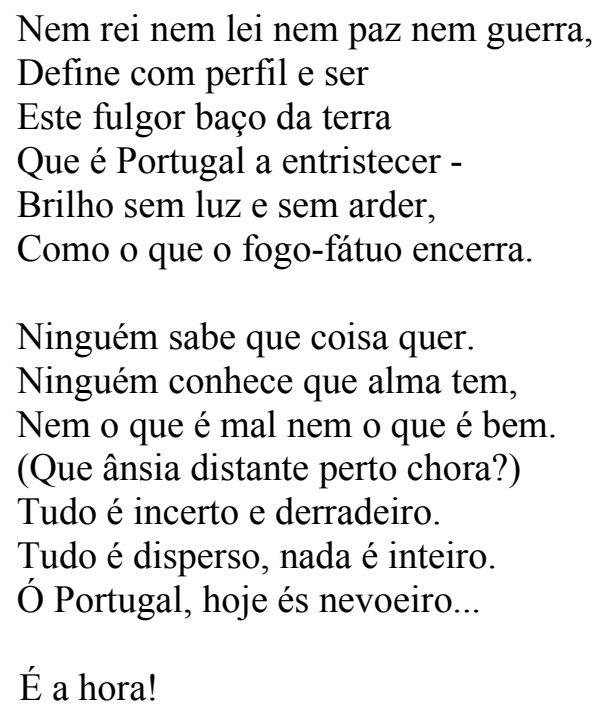

(PESSOA, s/d, p. 221)

Até que seja chegada a hora de partir, ou seja, do momento de epifania da narrativa, o leitor vai tomando conhecimento da viagem que o flaneur Ricardo Reis tem de cumprir. Se pensarmos no espelho como um objeto carregado de sentido simbólico no âmbito do romance de Saramago, por produzir apenas uma imagem de certa forma 
alterada em relação ao objeto projetado, temos que Ricardo Reis pode funcionar na obra como uma projeção de Fernando Pessoa. A noção do espelho como o projetor de uma figura que não existe (lembre-se de que Fernando Pessoa não consegue ver sua imagem projetada no espelho) pode nos levar a crer que Ricardo Reis também não existe, já que era apenas um fruto da imaginação do seu criador que morrera. O universo da ficção de Saramago aponta o espelho como uma superficie duas vezes enganadora, como é explicitado na passagem a seguir:

Ricardo Reis baixa o jornal, olha-se no espelho, superfície duas vezes enganadora porque reproduz um espaço profundo e o nega mostrandoo como mera projeção, onde verdadeiramente nada acontece, só o fantasma exterior das pessoas e das coisas, árvore que para o lago se inclina, rosto que nele se procura, sem que as imagens de árvore e rosto o perturbem, o alterem, lhe toquem sequer. (SARAMAGO, 1989 , p. 52)

O espelho pode ser tido, aqui, não como a superfície onde Narciso se desfaz, mas antes como o instaurador do engano de uma dupla realidade. O espelho, no romance de Saramago, presta-se ao engodo da existência de Fernando Pessoa e de Ricardo Reis, fruto da sua criação. Se a existência de Fernando Pessoa pode ser questionada a partir da sua morte no eixo da narrativa, a ideia de Ricardo Reis como projeção, nos leva a crer que a sua viagem também terminaria no evento da partida do poeta-criador. Já que o espelho é tido como uma superfície duas vezes enganadora, pelo fato de a projeção ser derivada de um objeto cuja existência é questionável (pois Fernando Pessoa está morto), podemos questionar também a existência de Ricardo Reis. Talvez o flaneur não seja mais que uma figura fantasmagórica que, assim como Pessoa, vagueia pelas ruas de Lisboa durante o conturbado ano de 1936.

Em O Ano da Morte de Ricardo Reis o trânsito do heterônimo, de volta para Portugal da Ditadura de Salazar, permite que ele esteja novamente ao lado de Fernando Pessoa, repetindo numa outra Lisboa encharcada pelas águas, a experiência de "filiação". Evocar o heterônimo pessoano na obra de ficção, mergulhada em dados históricos e nas águas turvas de um ano de mau tempo, deixa entrever, acima de tudo, a experiência de Saramago como leitor da História, da obra de Fernando Pessoa e de 
tantos outros, já que, como o autor mesmo assinala, todos os caminhos portugueses vão dar a Camões.

\section{REFERÊNCIAS BIBLIOGRÁFICAS:}

BENJAMIN, W. Charles Baudelaire: um lírico no auge do capitalismo. Trad. José Carlos Martins Barbosa, Hemerson Alves Baptista. Obras escolhidas, vol III. São Paulo: Brasiliense, 1994.

BERRINI, Beatriz (org.). José Saramago: uma homenagem. São Paulo: Educ, 1999.

MARGATO, Isabel. Lisboa reinventada n'O ano da morte de Ricardo Reis. PUC-RJ. Disponível em:

$<$ http://www.fflch.usp.br/dlcv/posgraduacao/ecl/pdf/via05/via05 11.pdf $>$ Acesso em: 18 Jul. 2009.

PESSOA, F. O guardador de rebanhos e outros poemas. São Paulo: Círculo do Livro, s/d, p. 221.

ROANI, Gerson L. O jornal como elemento de transfiguração da História em O ano da morte de Ricardo Reis, de Saramago. Revista Letras, Curitiba, n. 60, p. 153-176, jul./dez. 2003. Editora UFPR.

SARAMAGO, José. $O$ ano da morte de Ricardo Reis. São Paulo: Companhia das Letras, 1989. 